\title{
Experimental Study on Reasonable Spacing after Carbon Dioxide Presplitting in Low-Permeability Coal Seam
}

\author{
Zongyong Wei, ${ }^{1,2}$ Shugang Li, ${ }^{1,2}$ Haifei Lin,, Botao Li ${ }^{10},{ }^{1,2}$ Yang Ding, ${ }^{1,2}$ \\ and Haiqing Shuang ${ }^{1,2}$ \\ ${ }^{1}$ College of Safety Science and Engineering, Xi'an University of Science and Technology, Xi'an, Shaanxi 710054, China \\ ${ }^{2}$ Key Laboratory of Western Mine Exploitation and Hazard Prevention, Ministry of Education, \\ Xi'an University of Science and Technology, Xi'an, Shaanxi 710054, China
}

Correspondence should be addressed to Botao Li; 20120089021@stu.xust.edu.cn

Received 19 November 2020; Revised 19 February 2021; Accepted 6 March 2021; Published 19 March 2021

Academic Editor: Hualei Zhang

Copyright ( 92021 Zongyong Wei et al. This is an open access article distributed under the Creative Commons Attribution License, which permits unrestricted use, distribution, and reproduction in any medium, provided the original work is properly cited.

Gas disasters have been always a major hidden danger that affects mining safety in coal mines. Gas drainage by drilling is the fundamental method of gas control in coal mines. In view of the low-permeability coal seam, it is the basis of the safe and efficient production of the mine to take the measures of enhancing the permeability, improving the gas drainage efficiency, and shortening the drainage time. The $4^{-2}$ coal seam of the Jianxin coal mine in Shaanxi Province of China is a low-permeability coal seam. In order to obtain the reasonable hole spacing and the reasonable extraction time after the penetration enhancement, the pressure drop method is used to investigate the extraction radius. The results show that the gas pressure around the test hole decreases with time as a negative exponential function, and the effective radius of extraction increases with the increase of extraction time as a logarithmic function. Through the comparative analysis and variance analysis of the test data of the two drilling fields, it is proved that the data of the drainage radius of the two drilling fields are accurate and reliable. It is obtained that the reasonable spacing of the gas drainage holes is $8.10 \mathrm{~m}$ and the reasonable drainage time is 180 days after $\mathrm{CO}_{2}$ presplitting and permeability increase in the $4^{-2}$ coal seam of the mine.

\section{Introduction}

Coal is a basic energy source for industry and consumers [1]. Today, $37 \%$ of the world's electricity and $74 \%$ of the world's steel are produced with coal [2]. With the continuously strong demand for coal, the mining depth of mines is becoming increasingly deep. The mining depth of China's coal mines extends at a rate of 10-25 $\mathrm{m}$ every year [3], the gas content and gas pressure in the deep coal seams continue to increase, and the amount of gas emission also increases. Gas drainage can effectively reduce the gas content in a coal seam, effectively alleviate gas emissions in the process of coal mining, and improve the safety of mine production [4-6]. Additionally, gas is a clean and efficient energy source, and high concentrations of gas can be used to reduce greenhouse gas emissions and realize green mining in coal mines [7-9]. However, coal seams in China generally have the characteristics of high metamorphism and low permeability. In these seams, conventional extraction is difficult, gas predrainage takes a long time and cannot effectively eliminate the threats of gas disasters in mining and excavation faces, and the replacement of the working faces is often affected. Improving the permeability of the coal seam is the key to the successful implementation of gas predrainage and stimulation technology, such as water jet slotting, hydraulic fracturing, and $\mathrm{CO}_{2}$ precracking, requiring treatment to increase the permeability of the coal reservoir [10-12]. For a low-permeability coal seam, gas predrainage of coal seam gas is still an important technical means of gas control after enhancing the permeability, and the reasonable spacing of boreholes along the coal seam is one of the key parameters of gas drainage. If the distance between boreholes is too large, there is a blind area for drainage, which results in hidden dangers in the working face; if the distance between 
boreholes is too small, the construction boreholes in the working face are too dense, which increases the cost of gas drainage in the working face [13-15]. Scholars have performed much research on improving the efficiency of gas drainage and determining the reasonable spacing of gas drainage holes. Du and Yufei [16] systematically introduced equipment and technologies for the use of liquid carbon dioxide phase-transition explosion in underground mines. Chen et al. [17] conducted field tests of liquid carbon dioxide phase-transition explosion and concluded that liquid carbon dioxide phase technology can effectively improve coal seam permeability. To improve the sealing performance of gas drainage holes and promote gas drainage, Zheng et al. [18] developed a new type of two-phase grouting material and the related equipment and studied the sealing method of the two-phase grouting to improve the gas drainage performance of horizontal wells. Fan et al. [10] used COMSOL Multiphysics, the numerical simulation software, to establish a three-dimensional drilling model for gas drainage, and determined the equations relating the effective radius $R$ and influence radius $r$ with the gas drainage. Peng et al. [19] designed a physical model of gas drainage under different ground stress levels by using an independently developed multifield coupling physical simulation test system. According to the theory of gas flow in coal seams, Ji et al. [20] studied the distribution characteristics of the gas pressure in a coal body around a drainage borehole. Wang et al. [21] established a gas flow equation, taking the gas flow field around a drainage borehole as the research object.

A calculation formula for the critical residual gas pressure was established by Wen et al. [22], and it has made great contributions to the study of the reasonable spacing of gas drainage boreholes.

However, there are few studies on the variation in the pressure around extraction boreholes and the reasonable spacing of extraction boreholes after $\mathrm{CO}_{2}$ presplitting of coal seams. Based on field tests and theoretical analysis, this paper obtains the relationship between the extraction radius and the extraction time after $\mathrm{CO}_{2}$ presplitting in a lowpermeability coal seam of the Jianxin coal mine in Shaanxi Province of China and obtains the best reasonable hole spacing and extraction period, providing a theoretical basis for improving the gas drainage efficiency in a low-permeability coal seam.

\section{Materials and Methods}

2.1. Principle of $\mathrm{CO}_{2}$ Phase Transformation Cracking. The procedure of liquid $\mathrm{CO}_{2}$ phase-change cracking includes drilling holes in the target coal body, placing a blasting tube filled with liquid $\mathrm{CO}_{2}$ into the hole, and connecting the blasting tube and the detonator after sealing the hole to continuously increase the temperature of the $\mathrm{CO}_{2}$. When the temperature reaches the critical point of the gas-liquid phase change of $\mathrm{CO}_{2}$ (temperature $31^{\circ} \mathrm{C}$ and pressure $7.4 \mathrm{MPa}$ ), the $\mathrm{CO}_{2}$ rapidly transforms from the liquid phase to the gas phase, and the volume of the generated gas expands 600fold. When the high-pressure gas reaches the ultimate strength of the constant-pressure energy relief plate, it bursts through the constant-pressure energy relief plate and ejects from the discharge head. The coal body is broken by the impact force, and the original crack is expanded, resulting in media rupture $[23,24]$. The liquid $\mathrm{CO}_{2}$ phase-change cracking device is composed of a high-strength filling metal main pipe, a heater, a constant-pressure energy relief plate, a sealing gasket, a relief head, and other parts, as shown in Figure 1.

After the phase-change explosion of the liquid $\mathrm{CO}_{2}$, a strong stress wave and explosive gas are formed around the explosion vent, providing the main energy for the coal body to break through, and the energy accumulation pressure reaches $270 \mathrm{MPa}$. Under the impact of energy-release cracking, the coal around the borehole experiences radial compression and tangential tensile effects. When the circumferential tensile stress exceeds the ultimate tensile strength, the coal is damaged, and cracks are generated. When the shock wave decays along the path to lower than the tensile strength of the coal, cracks are no longer generated. Additionally, the gas-phase $\mathrm{CO}_{2}$ expands rapidly after the shock wave and enters the coal body along the initial guiding fracture. Due to the air wedge effect, the radial fracture or the primary fracture inside the coal body continues to expand until the $\mathrm{CO}_{2}$ pressure drops to the point where the fracture does not expand, and finally, a large number of conductive fractures centered on the borehole are formed in the coal body [25], which increases the permeability of low-permeability coal, as shown in Figure 2.

\subsection{The Basic Theory of Gas Drainage in Drilling.} Generally speaking, the permeability of the coal seam and gas supply amount of the borehole are limited, and the gas flow property of the coal seam is unstable flow, that is, with the increase of flow time, the gas flow intensity and flow rate of the borehole will decline. According to the theory of the coal seam gas flow, the gas flow expression of the gas drainage borehole is as follows [26, 27]:

$$
q_{0}=\frac{\lambda\left(p^{2}-p_{0}^{2}\right)}{R_{0} p_{\text {std }} \ln \left(R / R_{0}\right)},
$$

where $q_{0}$ is the initial strength of gas emission from the borehole, $\mathrm{m}^{3} /\left(\mathrm{min} \cdot \mathrm{m}^{2}\right), \lambda$ is the permeability coefficient of the coal seam, $\mathrm{m}^{3} /\left(\mathrm{MPa}^{2} \cdot \mathrm{d}\right), p$ is the original gas pressure of the coal seam, MPa, $p_{0}$ is the gas pressure in the borehole, $\mathrm{MPa}, R_{0}$ is the drilling radius, $\mathrm{m}, p_{\text {std }}$ is the gas pressure under the standard state, $\mathrm{MPa}$, and $R$ is the influence radius of the borehole gas flow field, $m$. According to the theory of the coal seam gas flow, the attenuation of borehole gas emission intensity conforms to the negative exponential function relationship, as shown in the following equation:

$$
q^{\prime}=q_{0} e^{-\alpha t}
$$

where $q^{\prime}$ is the gas emission intensity of the borehole at time $t, \mathrm{~m}^{3} /\left(\mathrm{min} \cdot \mathrm{m}^{2}\right), \alpha$ is the attenuation coefficient of the gas flow in the borehole, $\mathrm{d}^{-1}$, and $t$ is the gas flow time in the borehole, min. Then, the gas emission amount of the drilling hole at time $t$ is shown in the following equation: 

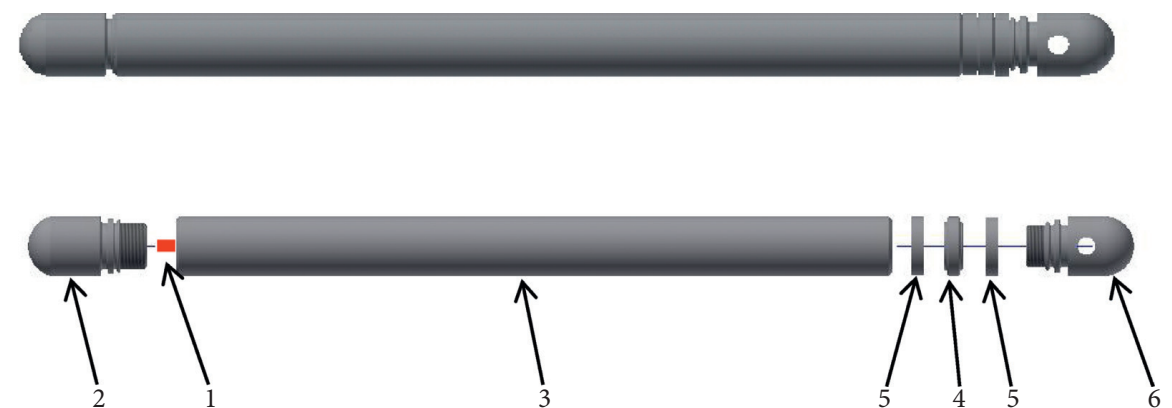

(1) Filling valve,

(2) Detonator,

(3) Main pipe of crack maker,
(4) Gasket,

(5) Constant pressure energy relief plate,

(6) Explosion head.

FIgURE 1: Schematic diagram of the liquid $\mathrm{CO}_{2}$ crack generator. (1) Filling valve. (2) Detonator. (3) Main pipe of the crack maker. (4) Gasket. (5) Constant-pressure energy relief plate. (6) Explosion head.

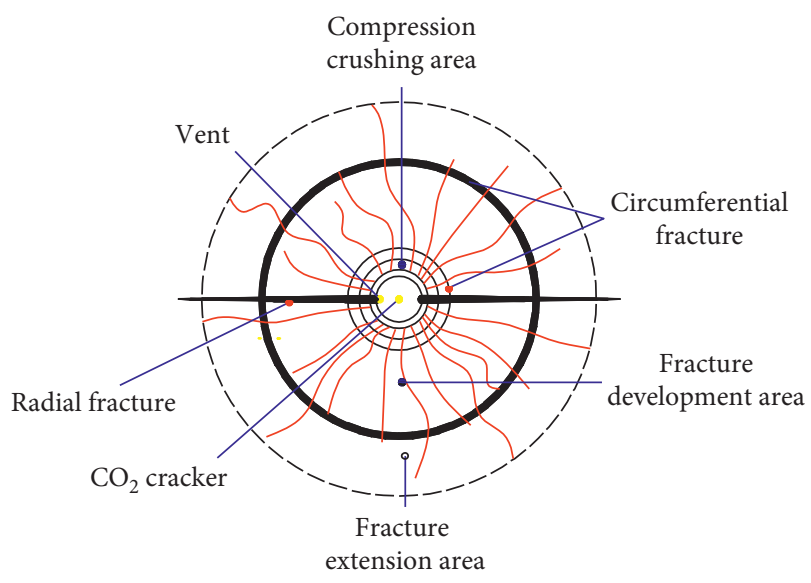

FIGURE 2: Fracture distribution of coal around the borehole caused by $\mathrm{CO}_{2}$ fragmentation.

$$
q=2 \pi R_{0} m q^{\prime}
$$

where $q$ is the gas emission amount of the drilling hole at time $t, \mathrm{~m}^{3} / \mathrm{min}$, and $m$ is the coal seam thickness or coal penetration length of the borehole, m. By equation (3), the relationship between total amount of gas drainage and drainage time in a certain period after borehole drainage is obtained:

$$
\begin{aligned}
Q & =\int_{0}^{t} q d t=\frac{2 \pi R_{0} m q_{0}}{\alpha}\left(1-e^{-\alpha t}\right) \\
& =\frac{2 \pi m \lambda\left(p^{2}-p_{0}^{2}\right)}{\alpha p_{\text {std }} \ln \left(R / R_{0}\right)}\left(1-e^{-\alpha t}\right) .
\end{aligned}
$$

According to the law of conservation of mass, it can be concluded that

$$
Q=\int_{R_{0}}^{R_{1}} f(2 \pi R m \rho w \eta) d R,
$$

where $R$ is the drainage radius, $\mathrm{m}, \rho$ is the coal density, $\mathrm{kg} / \mathrm{m}^{3}$, $w$ is the coal seam gas content, $\mathrm{m}^{3} / \mathrm{t}, \eta$ is the coal seam predrainage rate, $\%, R_{0}$ is the drilling radius, $\mathrm{m}$, and $R_{1}$ is the presplitting permeability increasing drainage radius, $\mathrm{m}$. By integrating equation (5), we can get the following results:

$$
\left(R_{1}^{2}-R_{0}^{2}\right)=\frac{Q}{\pi R m \rho w \eta} .
$$

Because the radius of the effective radius of $\mathrm{CO}_{2}$ precracking enhancement is much larger than the radius of the borehole, the combined equation (4) can be obtained: $R_{1}=\sqrt{(Q /(Q /(\pi R m \rho w \eta)))}$. The gas drainage radius of boreholes is mainly related to the gas content, permeability coefficient, diameter and negative pressure of the drilling hole, extraction purpose, and time. The larger the permeability coefficient of the coal seam, the larger the diameter of the borehole, the greater the negative pressure of drainage, and the longer the drainage time, and the greater the thickness of the coal seam, the greater the amount of gas drainage by the borehole. Generally, in a specific area, after the borehole diameter and suction negative pressure are determined, the coal seam thickness and permeability coefficient can be considered as certain values. Therefore, the relationship between the gas drainage capacity of the borehole and the drainage time is $\left(1-e^{-\alpha t}\right)$. According to the relationship between the drilling drainage capacity and the drainage radius, the drainage radius corresponding to the different drainage time of the borehole can be obtained.

According to the current research, the methods for determining the reasonable spacing of gas drainage boreholes mainly include theoretical analyses, numerical simulations, and field measurements. The field investigations are mainly divided into the following: the gas pressure reduction method, gas content reduction method, tracer gas method, and borehole gas flow method. As field investigation provides a reasonable spacing of boreholes that gives the most accurate and comprehensive reflection of the coal seam characteristics, the pressure drop method is used to determine the reasonable spacing of gas drainage boreholes. The 2016 edition of China's Coal Mine Safety Regulations clearly stipulates that, after predrainage of coal seam gas, the outburst prevention and control effect of predrainage gas must be tested. One of the indicators for testing is that the predrainage of coal seam gas is greater than $30 \%$, that is, the 
gas content after drainage is less than $30 \%$ of that before drainage. Under the premise that industrial application error is allowed, there is a parabolic relationship between the gas pressure $P$ and gas content $W$. First, a parabolic equation is proposed to approximately replace the coal seam gas content curve:

$$
W=a \sqrt{P}
$$

where $W$ is the coal seam gas content, $\mathrm{m}^{3} / \mathrm{t}, a$ is the coal seam gas content coefficient, and $P$ is the coal seam gas pressure, $\mathrm{MPa}$.

Therefore, there is a parabolic relationship between the ratio of the gas content reduction and the gas pressure reduction before and after extraction. If the predrainage rate of the coal seam is $30 \%$, the residual gas content is $70 \%$ of the original gas, i.e., $W^{\prime}=0.7 \mathrm{~W}$. Substituting equation (7), $p^{\prime}=0.49 p$. Through calculation, the residual gas pressure is $49 \%$ of the original gas pressure, and the gas pressure drop is $51 \%$. According to the above theoretical basis, the reasonable hole spacing is determined.

\section{Reasonable Spacing Test of $\mathrm{CO}_{2}$ Presplitting Gas Drilling}

3.1. General Conditions of the Mine. The terrain of the Jianxin coal mine in Shaanxi Province is high in the southwest and low in the northeast, with a general elevation of $+1350-1600 \mathrm{~m}$, a general elevation difference of 200-300 m, and a maximum elevation difference of $559 \mathrm{~m}$. Coal seam $4^{-2}$ is mainly mined from the top of the next stage cycle in the first section of the Yan'an formation, which is layered. The burial depth of the coal seam is $433-810 \mathrm{~m}$, and most of the seam is at depths in the range of $520-700 \mathrm{~m}$. The thickness of the coal seam is $0.0-11.74 \mathrm{~m}$, with an average thickness of $5.68 \mathrm{~m}$. The main part (the center of the ancient depression) of the coal seam is stable at $4-10 \mathrm{~m}$, with an average of $8.33 \mathrm{~m}$. The coal seam gradually thins from the center of the depression to the surrounding area and is the most stable coal seam in the area. The adsorption constant $a$ value is $17.211 \mathrm{~m}^{3} / \mathrm{t}$, the $b$ value is $0.593 \mathrm{MPa}^{-1}$, the gas content value is $5.26-5.90 \mathrm{~m}^{3} / \mathrm{t}$, the natural gas flow attenuation coefficient of the borehole is $0.040-0.048 \mathrm{~d}^{-1}$, and the permeability coefficient of the coal seam is $0.20-0.33 \mathrm{~m}^{2}$ / $\left(\mathrm{MPa}^{2} \cdot \mathrm{d}\right)$. This coal seam is a low-permeability coal seam. To effectively increase the permeability of the coal seam and improve the gas drainage efficiency, $\mathrm{CO}_{2}$ presplitting-enhanced permeability technology is used.

3.2. Test Site. Based on the field survey of the $4^{-2}$ coal seam in the Jianxin coal mine, two gas drainage drilling fields (24 and 25 ) along the return air chute of the 4203 working face were selected (see Figure 3). The 4203 working face is $220 \mathrm{~m}$ long and $2880 \mathrm{~m}$ long, and the average thickness of the coal seam is $6.5 \mathrm{~m}$. The 24 and 25 drilling fields are not drilled, and the final location of the extraction hole in the 24 drilling field is $90 \mathrm{~m}$ away from that in the 25 drilling field. The coal seams in the two drilling fields are stable, and there is no geological structural fracture zone; the drilling field construction does not affect the passage or construction work of personnel and vehicles in the roadway, meeting the test conditions.

3.3. Test Flow. The measurement process of the extraction radius is shown in Figure 4.

At first, four parallel gas-pressure test holes were constructed in the No. 24 and No. 25 drilling field of the 4203 return air chute, with parallel spacings of $1.5 \mathrm{~m}, 4.5 \mathrm{~m}, 2.0 \mathrm{~m}$, and $1.0 \mathrm{~m}$ (Figure 5). During the drilling construction, we ensured that the four pressure drilling holes were parallel to each other and perpendicular to the coal wall, with a drilling diameter of $94 \mathrm{~mm}$, hole depth of $60 \mathrm{~m}$, and elevation angle of $9^{\circ}$. After the formation of the boreholes, the cuttings and water in the boreholes were blown with compressed air to make the borehole walls smooth and straight to ensure the sealing quality of the pressure tap.

Then, after the completion of the pressure measurement drilling, the hole sealing work shall be carried out, and the pressure-measuring equipment shall be installed 24 hours after the completion of the sealing. Before sealing, we prepared the sealing materials, instruments, tools, etc. According to the selected sealing method, we checked whether the pressure pipe was unobstructed and whether its connection with the pressure gauge was airtight. To effectively ensure a sealing depth of $45 \mathrm{~m}$, polyurethane was used to seal the first $3 \mathrm{~m}$, grouting cement was used to seal the next $42 \mathrm{~m}$, and the measuring air chamber was $15 \mathrm{~m}$ (Figure 6). After sealing the hole, we observed the gas pressure until the pressure was stable.

Finally, after the reading from the pressure gauge was stable, a drilling machine was used to construct gas drainage holes between the $2 \#$ and $3 \#$ pressure holes in the 24 and 25 drilling field to ensure that the drainage holes and pressure holes were in a straight line; the diameter of the drainage hole was $113 \mathrm{~mm}$, the depth of the hole was $60 \mathrm{~m}$, and the elevation angle was $9^{\circ}$. $\mathrm{CO}_{2}$ presplitting blasting: after the completion of the extraction drilling, the $\mathrm{CO}_{2}$ presplitting blasting was carried out in the $45-60 \mathrm{~m}$ section, with all the presplitting parameters the same as the previous mining parameters. After presplitting, the gas drainage holes were sealed at a length of 12-14 m. After the completion of hole sealing, the pipe was connected for pumping, the negative pressure was $15 \mathrm{kPa}$, and the pressure gauge of each test hole was read every day for approximately 30 days.

\section{Results}

4.1. Coal Seam Gas Pressure. In the Jianxin coal mine, there were 8 holes in the 24 and 25 drilling field for the gas pressure field test, which took 54 days. The active pressure measurement method was adopted in No. 1 hole of No. 24 drilling field. Finally, the pressure measurement failed due to the construction damage of the water sump in the roadway, and the pressure measurement of the remaining 7 holes was successful. The observation results are plotted on a coordinate chart with time (d) as the abscissa and gas pressure $(\mathrm{MPa})$ as the ordinate. The pressure curve is shown in Figures 7 and 8 . 


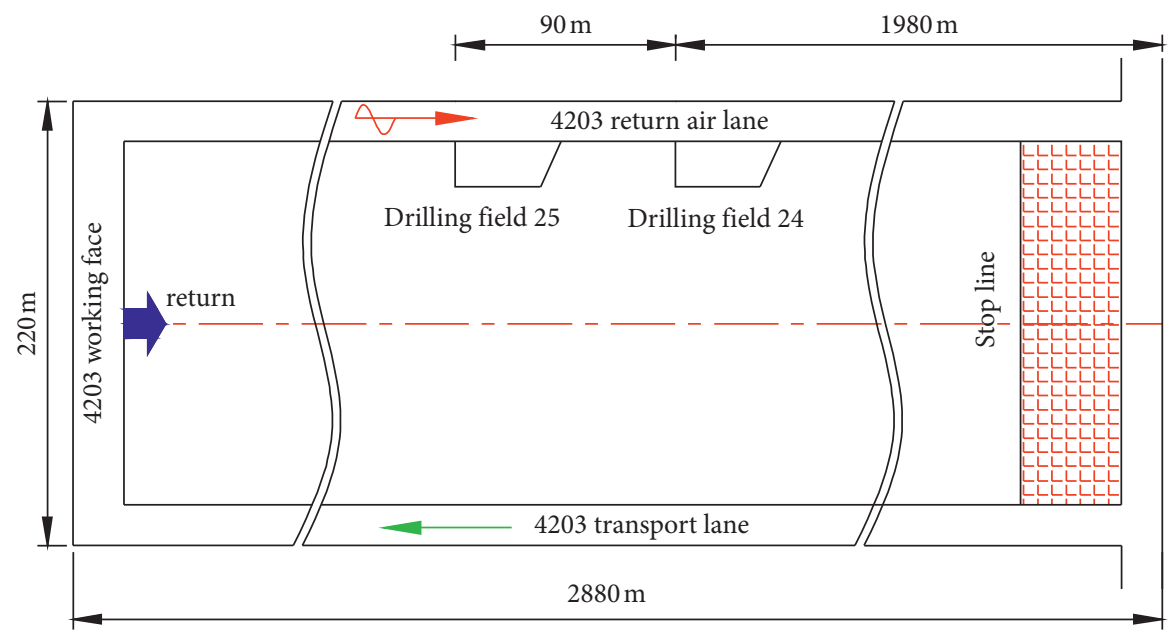

Figure 3: Location of the 24 and 25 gas drainage drilling field.
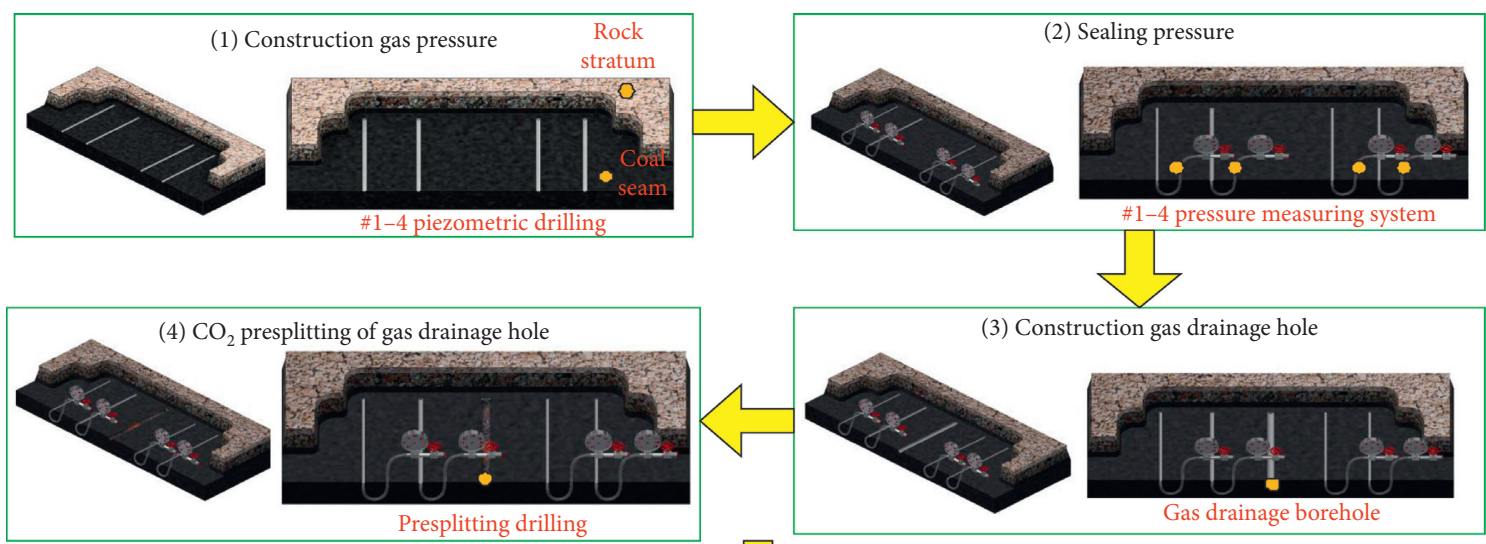

Presplitting drilling

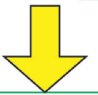

(5) Pumping by connecting pipes and measuring the pumping radius

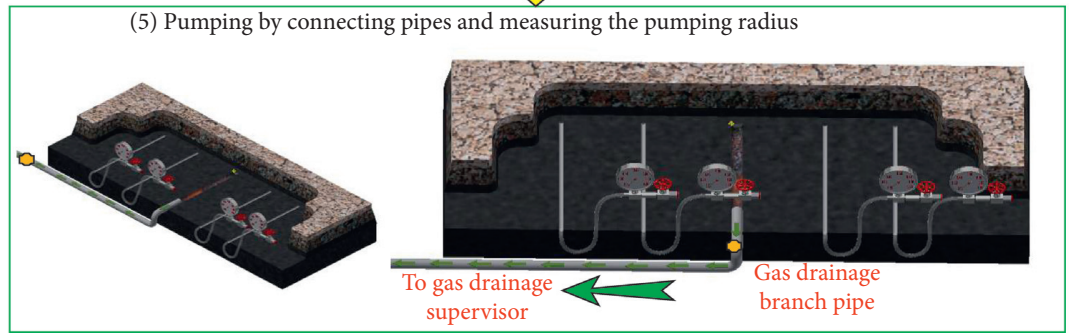

FiguRE 4: Field measurement process of the extraction radius.

It can be seen from Figures 7 and 8 that except for No. 1 hole of No. 24 drilling field, the borehole pressure trend increased rapidly in the first 10 days of the drainage period, and the borehole pressure gradually stabilized with the increase of time. The drilling pressure of No. 24 drilling field No. 2 hole was the largest, reaching about $0.45 \mathrm{MPa}$, and the drilling pressure of No. 25 drilling field No. 3 was the smallest, about $0.15 \mathrm{MPa}$ during the stable period.

4.2. The Reasonable Spacing of Gas Drainage Boreholes. After the pressure measurement is stable, the continuous pipe pumping is started according to the test steps. The more gas drainage distance is, the slower the gas drainage pressure decreases. After 30 days, according to the changes in the extraction time and gas pressure value, the data were analyzed, the gas pressure curve of each test hole was drawn, and the data were fitted by functions. Figure 9 shows the fitting results for the pressure change of the test hole in the No. 24 drilling field.

According to the fitting formula, the gas pressure of test holes 2-4\# decreases as a negative exponential function with the extraction time. After a certain period of extraction, the gas pressure drops below the effective radius of extraction, so the extraction is considered effective. After calculation, holes 2-4\# decrease to below the effective extraction radius after 


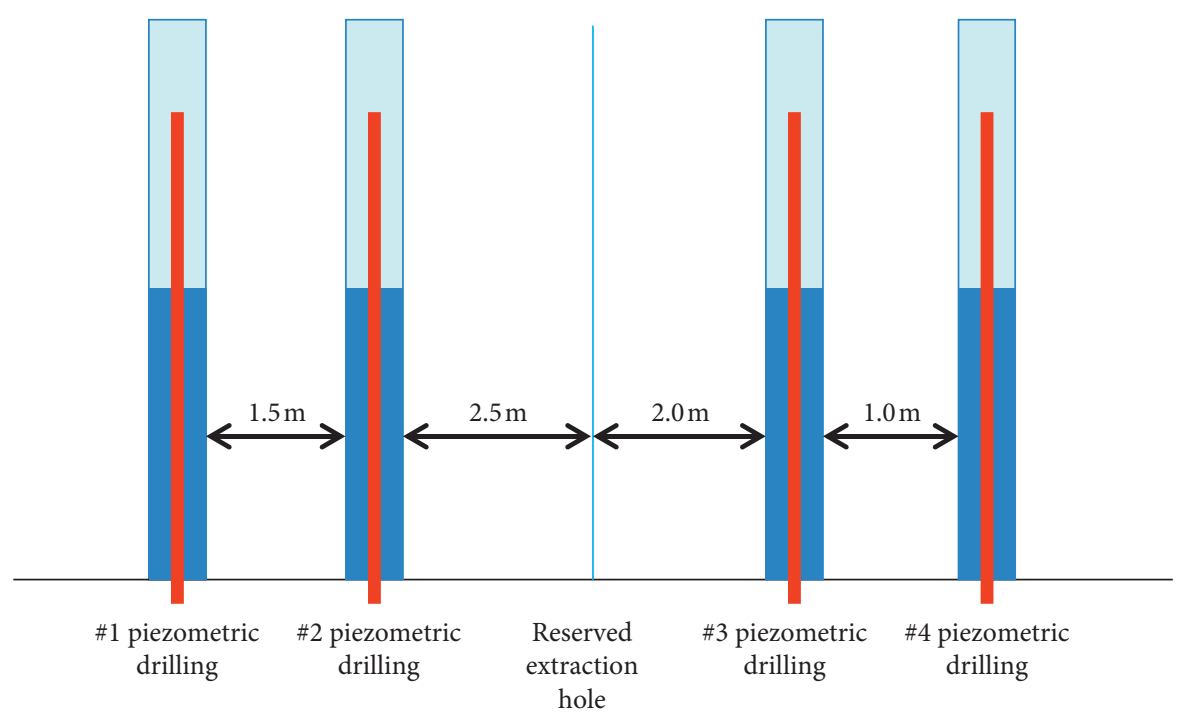

FIGURE 5: Layout of the pressure-measuring borehole.

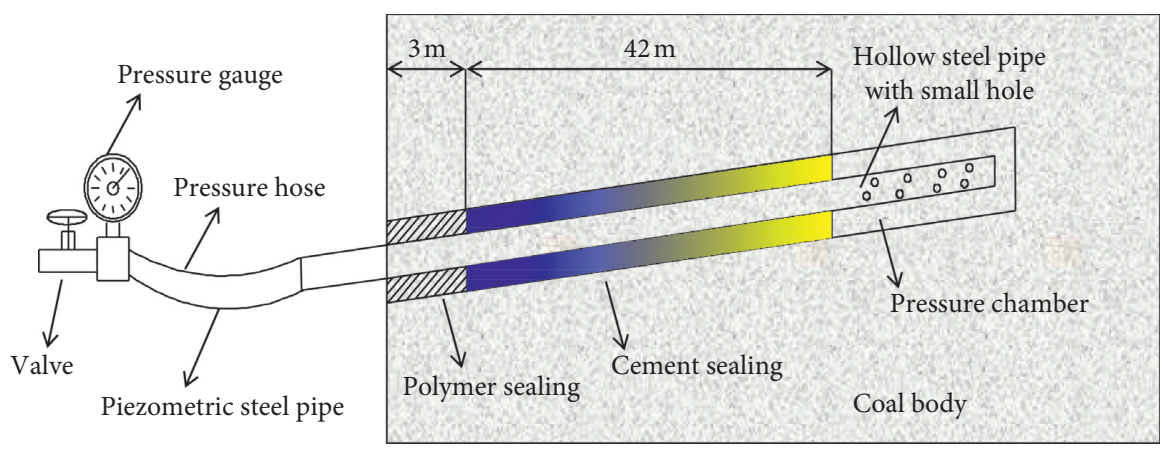

Figure 6: Schematic diagram of pressure hole sealing.

$45 \mathrm{~d}, 32 \mathrm{~d}$, and $100 \mathrm{~d}$, respectively. Due to the pressure relief of hole 1\#, the data of No. 25 drilling field are selected for the $155 \mathrm{~d}$ data for hole $1 \#$. Regression analysis is used to fit the extraction radius data over time for boreholes 1-4\#. The fitting curve and formula are shown in Figure 10 and equation (8).

After the $\mathrm{CO}_{2}$ presplitting of the coal seam in the No. 24 drill field of the 4203 return air channel in the Jianxin coal mine, the extraction radius increases as a logarithmic function with increasing extraction time, and the fitting formula is as follows:

$$
R=1.14291 * \ln (T)-1.95979,
$$

where $R$ is the effective radius of extraction in units of $m$ and $\mathrm{T}$ is the extraction time in units of $\mathrm{d}$.

According to the correlation between the extraction radius $R$ and the extraction time $t$ of the No. 24 drilling field, the extraction radius of different extraction times after $\mathrm{CO}_{2}$ presplitting of the coal seam can be calculated according to equation (2), as shown in Table 1.

Through the test, the readings of the pressure gauges in the No. 25 drilling field decrease with time; the closer to the extraction hole the gauge is, the faster the gas pressure decreases, and the farther away, the slower the gas pressure decreases. After 30 days, according to the changes in the gas pressure values with the extraction time, the data were analyzed, the gas pressure curve of each test hole was drawn, and the data were fit with a function; see Figure 11 for the pressure curves with time.

According to the fitting formula, the gas pressure of the 1-4\# test holes decreases as an exponential function with the extraction time. After a certain period of extraction, the gas pressure drops below the effective radius of extraction. It took $155 \mathrm{~d}, 46 \mathrm{~d}, 45 \mathrm{~d}$, and $92 \mathrm{~d}$ for the gas pressure in holes $1-4 \#$ to fall below the effective extraction radius, respectively. The data of the extraction radius with the extraction time for holes 1-4\# were fitted by regression analysis. The fitting curve and formula are shown in Figure 12 and equation (9).

For the $\mathrm{CO}_{2}$ presplitting of the coal seam in the No. 25 drill field of the 4203 return air channel in the Jianxin coal mine, the matching formula of the extraction radius and extraction time is as follows:

$$
R=1.37949 * \ln (T)-3.05697
$$

In the formula, $R$ is the effective radius of extraction in units of $\mathrm{m}$ and $T$ is the extraction time in units of $\mathrm{d}$. 


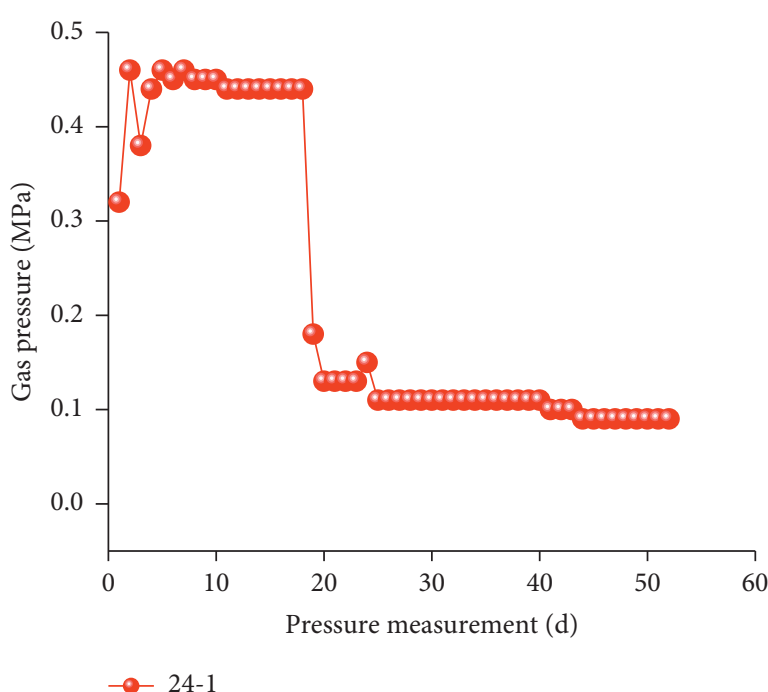

(a)

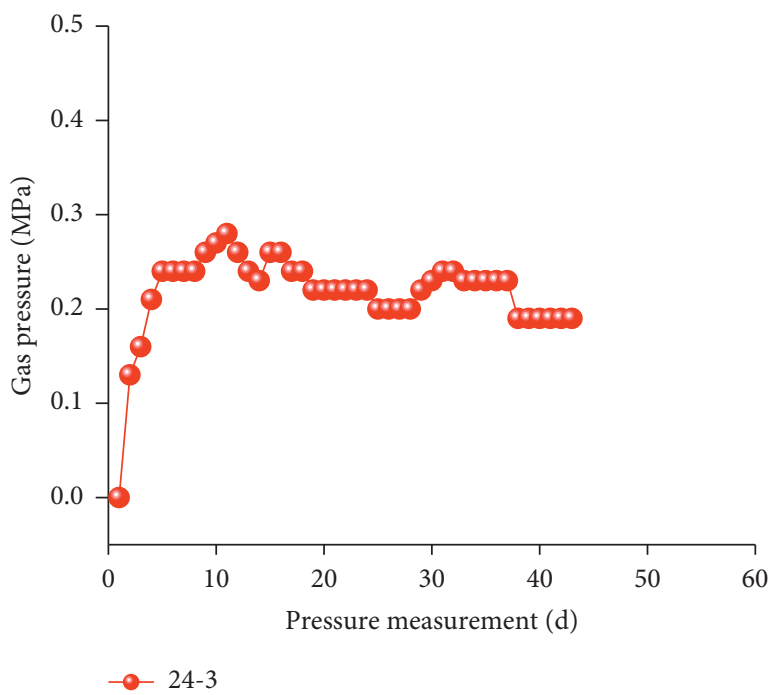

(c)

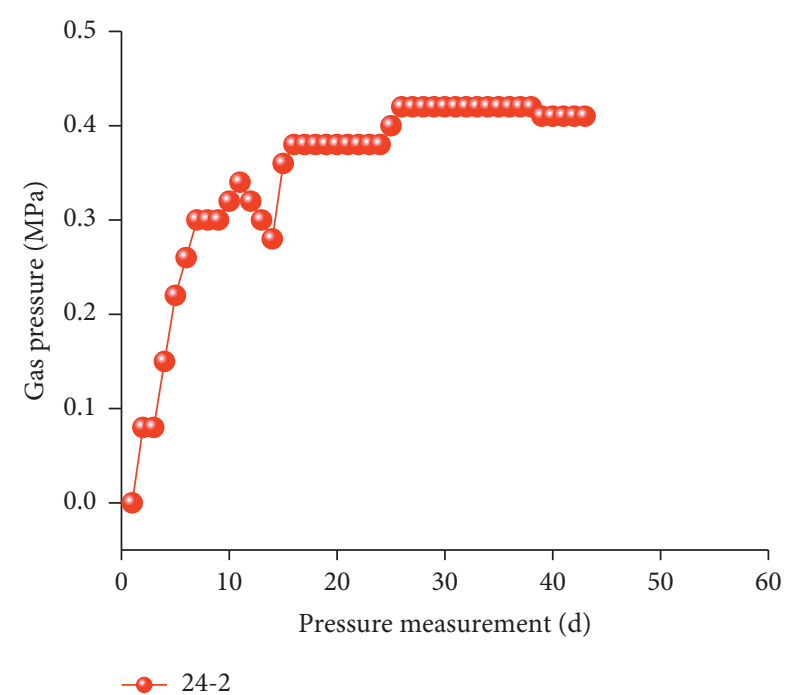

(b)

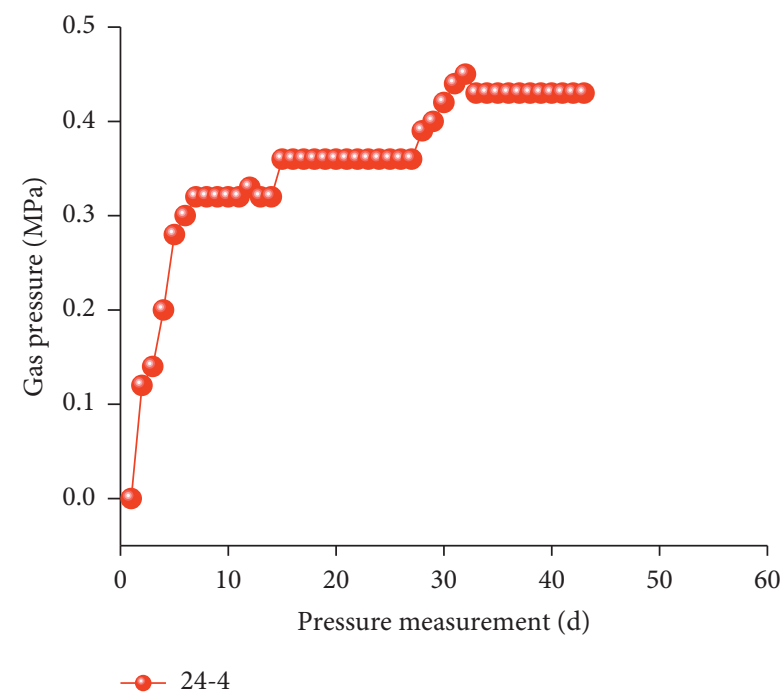

(d)

FIgURE 7: Gauge pressure and time curve of the No. 24 drilling field.

According to the correlation between the extraction radius $R$ and extraction time $t$ expressed by formula (9), the extraction radius at different extraction times after $\mathrm{CO}_{2}$ presplitting of the coal seam can be obtained in the No. 25 drilling field, as shown in Table 2.

\section{Discussion}

5.1. Reliability Analysis of Extraction Radius. The No. 24 and No. 25 drilling fields are $50 \mathrm{~m}$ apart in the 4203 working face of the Jianxin coal mine. There are no faults, collapse columns, or other geological structures in the coal seams between the drilling fields, and the coal seams are gentle. In order to determine the accuracy and reliability of the two groups of extraction radius data, the significance of the two groups of data was analyzed by ANOVA with drilling field factors and time factors.

The time factor analysis of variance is shown in Table 3; the analysis of variance is shown in Table 4.
Taking the significance level $\alpha=0.05$, the analysis shows that the time factor $F_{\mathrm{B}}$ value is 46.7541 , which is far greater than the critical value of $F(f 0.05(15,16)=2.35)$, indicating that the extraction time has great influence on the extraction radius.

Taking the significance level $\alpha=0.05$, the analysis shows that the $F_{\mathrm{A}}$ value of the drilling field factor is 0.0003 , which is far less than the critical value $f 0.05(1,14)=4.60$ of significance level $\alpha=0.05$, which indicates that the influence of different drilling fields on the gas drainage radius is minimal, which indirectly proves that the two groups of data are accurate and reliable.

Therefore, to effectively eliminate the error caused by the test operation and better reflect the extraction radius of different extraction times, we take the arithmetic average value of the two groups of data as the final extraction radius, as shown in Table 5.

5.2. Reasonable Spacing and Prepumping Period. The efficiency of gas drainage is affected by many factors. The study shows that the flow of gas in the borehole has radial 


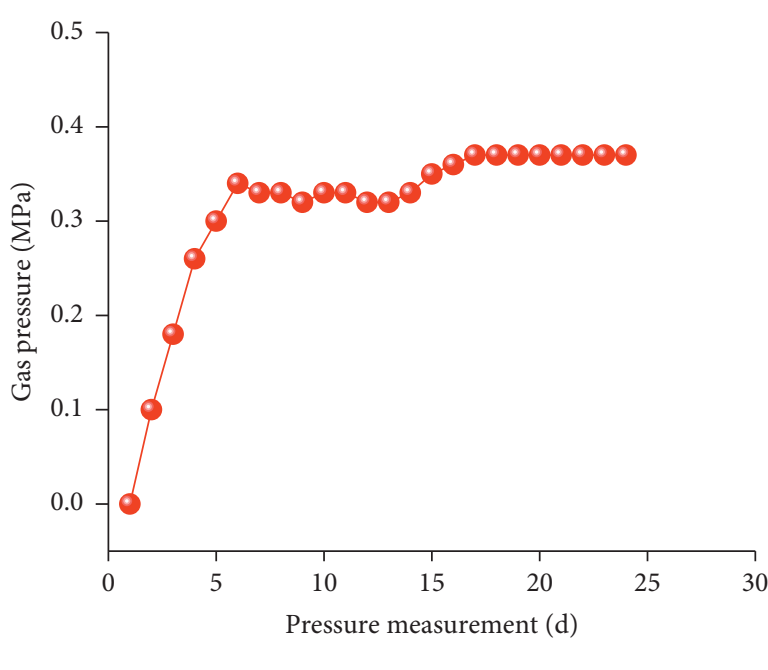

(a)

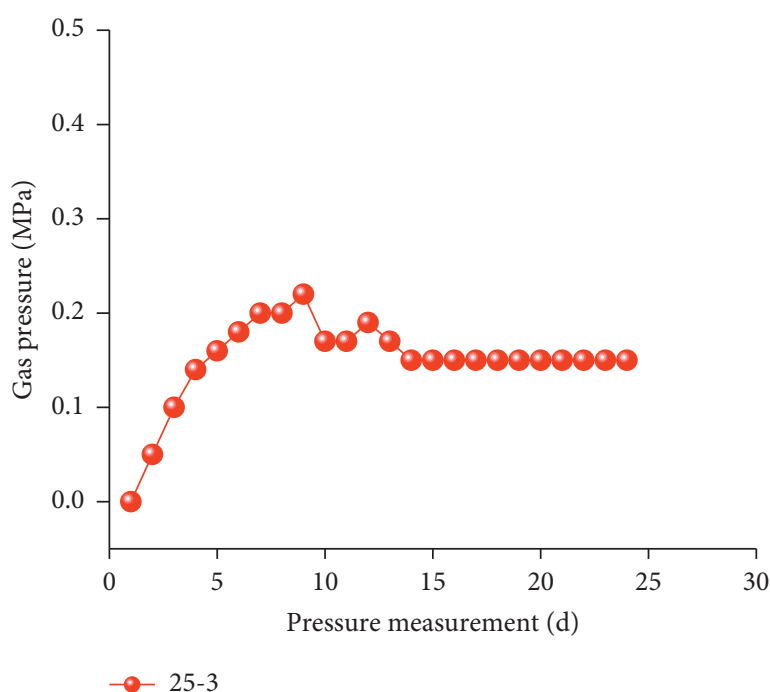

(c)

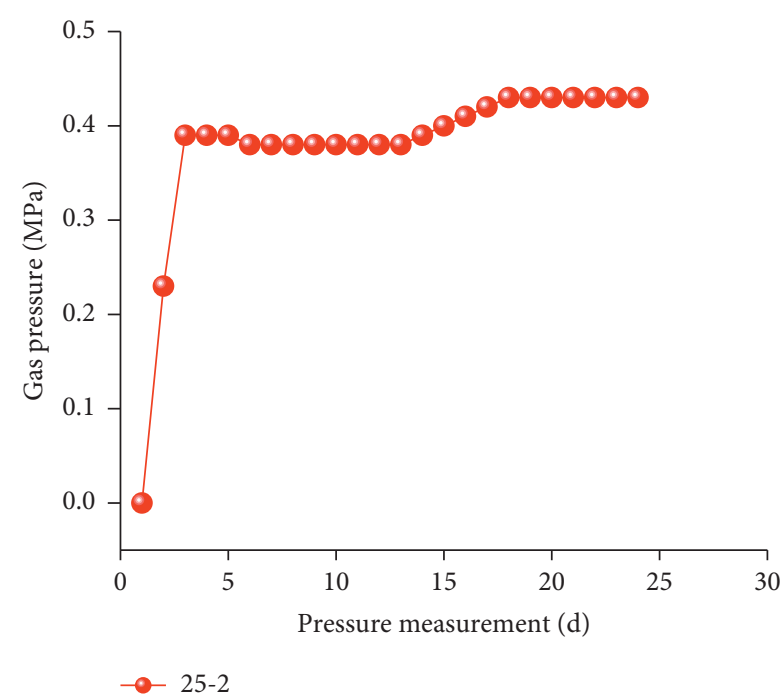

(b)

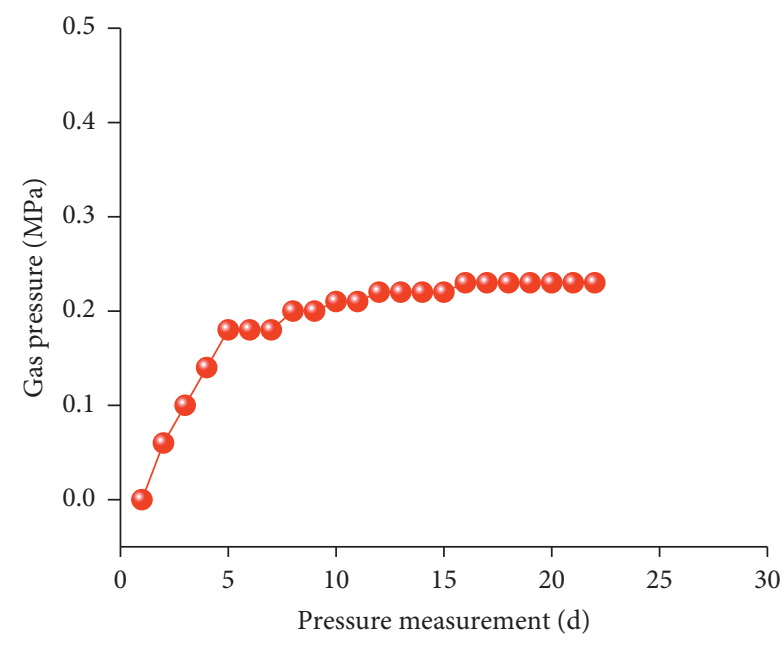

- 25-4

FIgURE 8: Gauge pressure and time curves of the No. 25 drilling field.

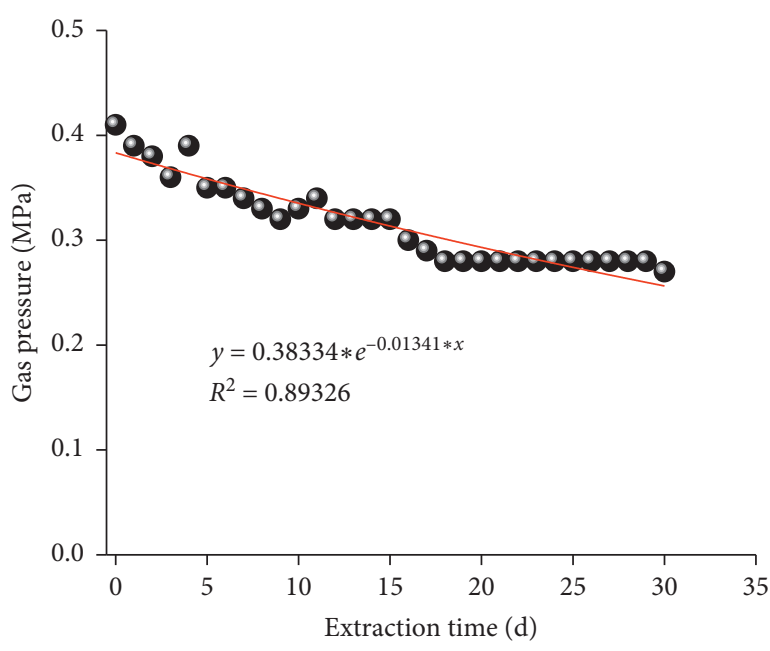

- 24-2

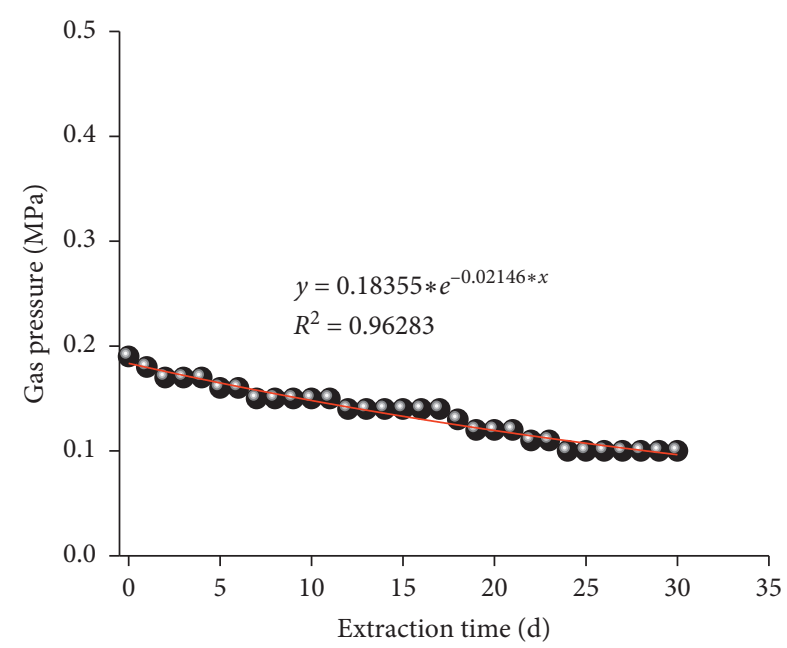

- 24-3

(a) 


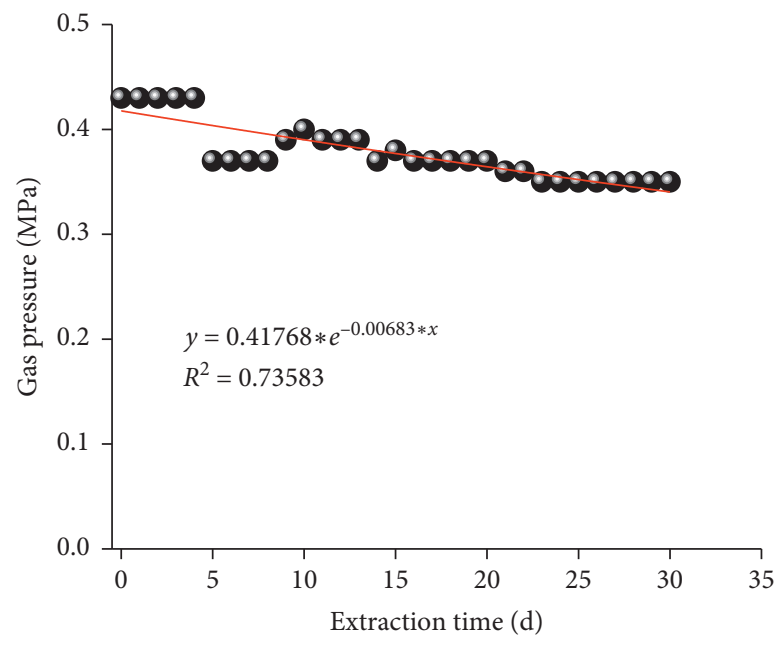

- $24-4$

(c)

Figure 9: Pressure attenuation of test holes 2-4\# in No. 24 drilling field.

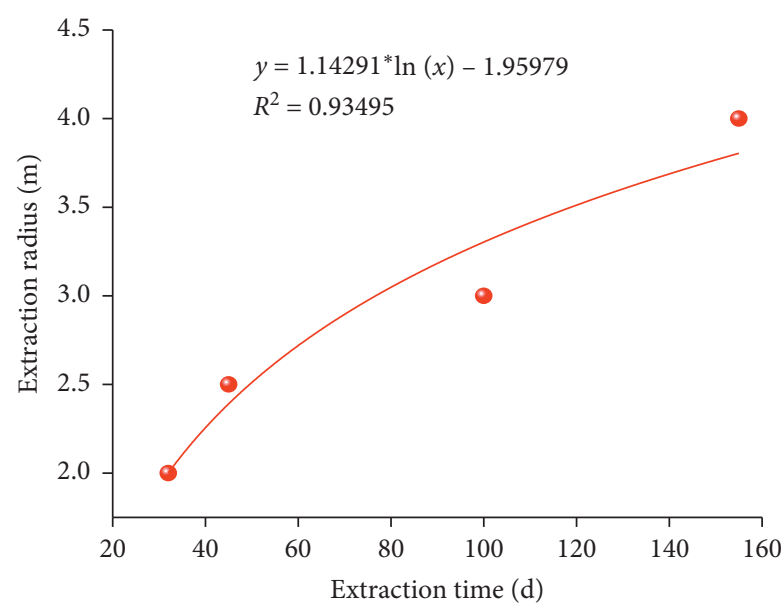

FIgURE 10: Fitting curve of the extraction radius with time in No. 24 drilling field.

TABLE 1: Extraction radius at different extraction times.

\begin{tabular}{lcccccccc}
\hline Extraction time (d) & 30 & 40 & 50 & 60 & 70 & 80 & 90 & 100 \\
\hline Extraction radius (m) & 1.93 & 2.26 & 2.51 & 2.72 & 2.90 & 3.05 & 3.18 & 3.30 \\
Extraction time (d) & 110 & 120 & 130 & 140 & 150 & 160 & 170 & 180 \\
Extraction radius (m) & 3.41 & 3.51 & 3.60 & 3.69 & 3.77 & 3.84 & 3.91 & 3.98 \\
\hline
\end{tabular}

instability when the coal seam gas is extracted by drilling. After gas drainage is carried out for a certain period of time, with increasing extraction time, the increase of extraction radius slows significantly.

In the Jianxin coal mine, the coal seam with $\mathrm{CO}_{2}$ presplitting and antireflection has a large fracture development area in the coal body. Additionally, due to the effect of the blasting force, the surrounding coal body is loose, broken, and creeping, which greatly enhances the permeability of the coal body around the borehole. It can be seen from the fitting curve that the effective radius of extraction increases with increasing preextraction time after presplitting of $\mathrm{CO}_{2}$; when the extraction time increases equally with the attenuation of gas pressure after 180 days of extraction, the percentage of the increase in the effective radius of drilling decreases gradually. Considering the drilling conditions, the working capacity of the presplitting equipment, and other factors, combined with the field test results of the 4203 working face, it is suggested that the reasonable extraction period of the $4^{-2}$ coal seam $\mathrm{CO}_{2}$ presplitting and antireflection coal seam in the 4203 working face is 180 days, the effective extraction radius is 


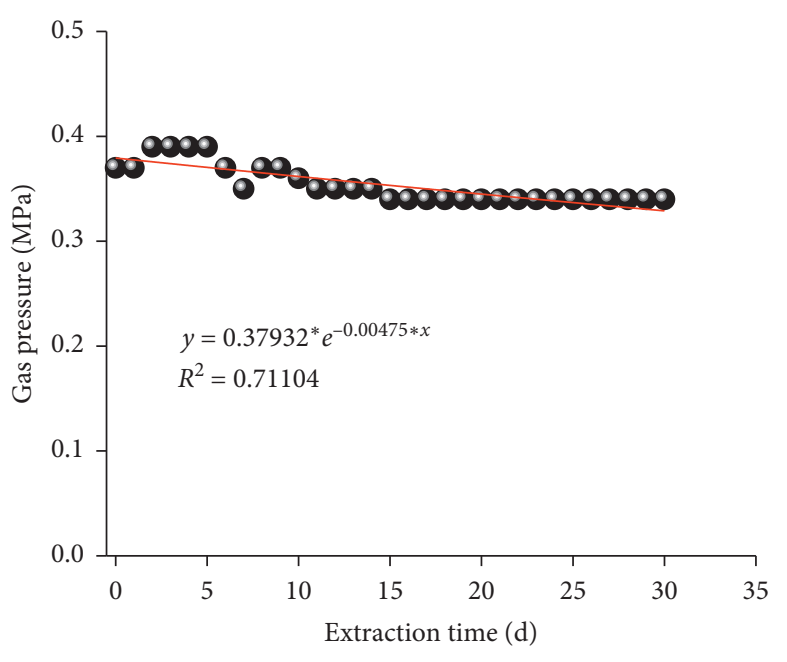

- 25-1

(a)

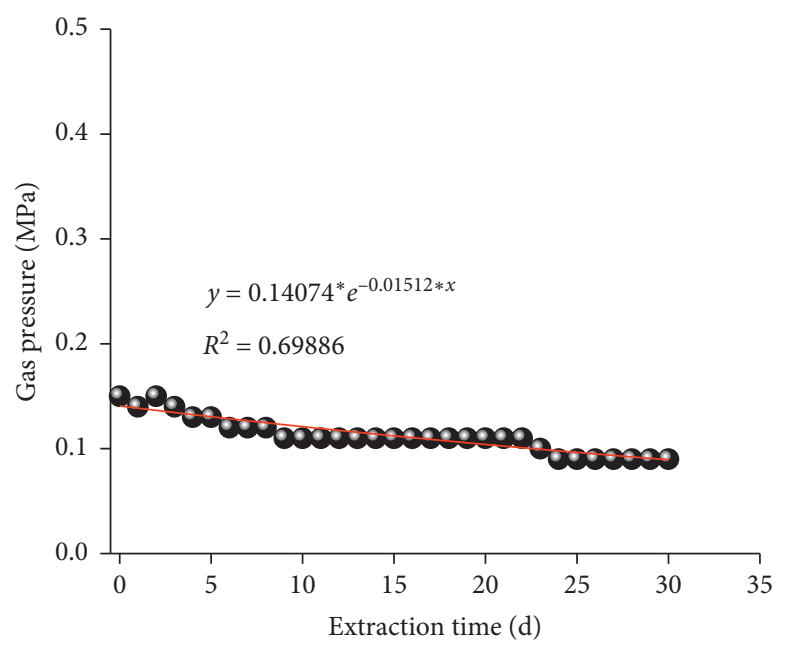

- 25-3

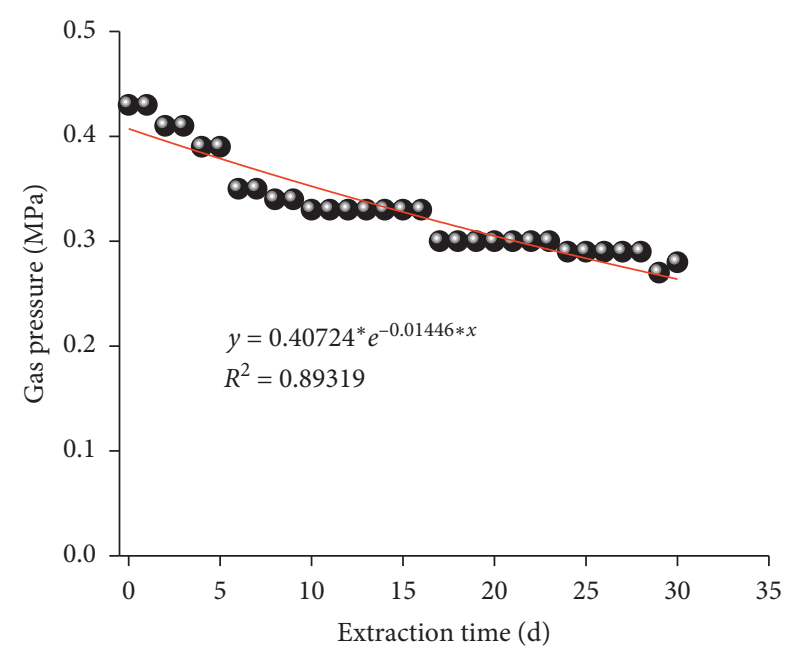

- 25-2

(b)

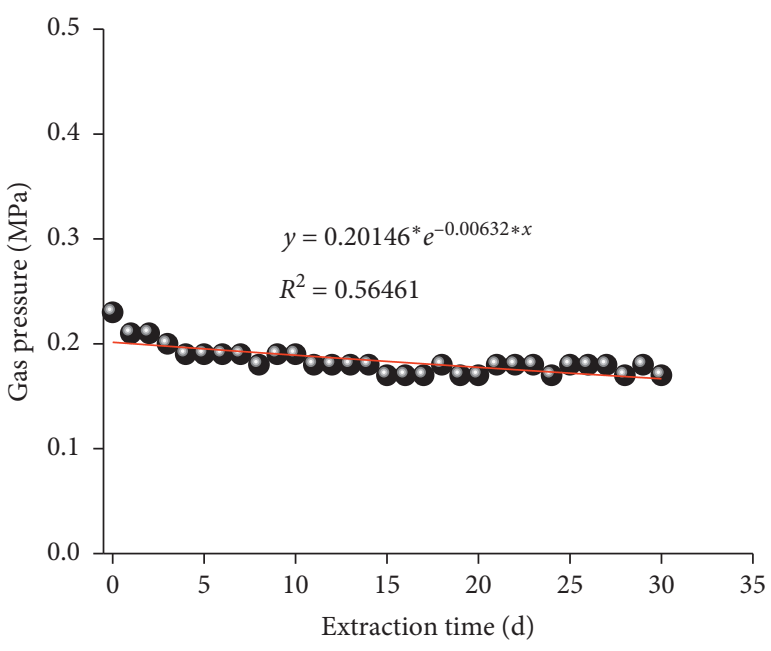

- 25-4

(c)

(d)

Figure 11: Pressure attenuation of test holes 1-4\# in No. 25 drilling field.

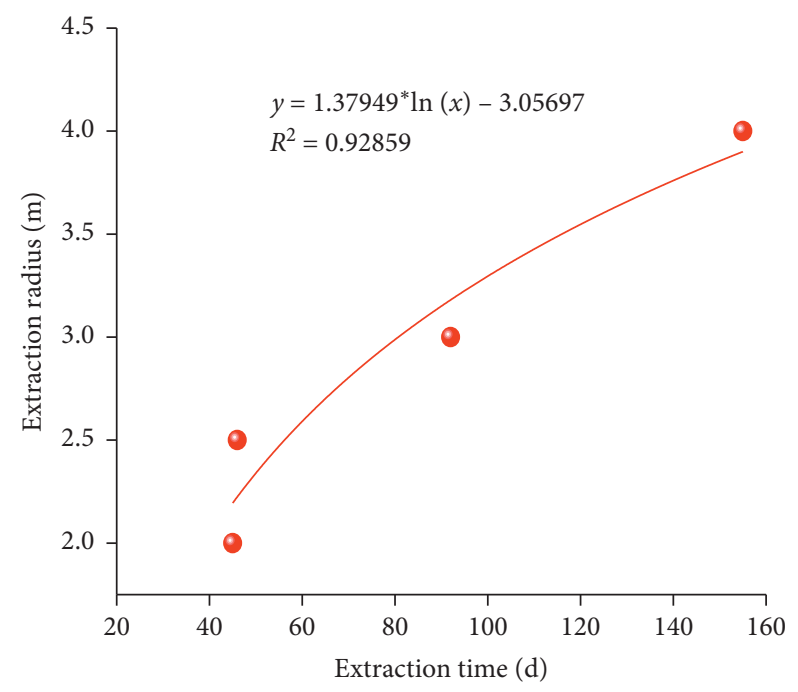

FIGURE 12: Fitting curve of the extraction radius with extraction time in the No. 25 drilling field. 
TABle 2: Extraction radius at different extraction times.

\begin{tabular}{lcccccccc}
\hline Extraction time (d) & 30 & 40 & 50 & 60 & 70 & 80 & 90 & 100 \\
\hline Extraction radius (m) & 1.63 & 2.03 & 2.34 & 2.59 & 2.80 & 2.99 & 3.15 & 3.30 \\
Extraction time (d) & 110 & 120 & 130 & 140 & 150 & 160 & 170 & 180 \\
Extraction radius (m) & 3.43 & 3.55 & 3.66 & 3.76 & 3.86 & 3.94 & 4.03 & 4.11 \\
\hline
\end{tabular}

Table 3: Variance analysis of time factor experimental results.

\begin{tabular}{|c|c|c|c|c|c|c|}
\hline Factors & Sum of deviation squares $\left(\mathrm{SS}_{\mathrm{i}}\right)$ & Freedom (df) & Mean square deviation (MS) & $F_{\mathrm{A}}$ & $F_{0.05}(1,14)$ & Significance \\
\hline Drilling field (A) & 6.9706 & 15 & 0.41003 & 46.7541 & 2.35 & Remarkable \\
\hline Error $(\mathrm{E})$ & 0.1316 & 16 & 0.00877 & - & - & - \\
\hline Sum $(\mathrm{T})$ & 7.1022 & 31 & - & - & - & - \\
\hline
\end{tabular}

TABLE 4: Variance analysis of drilling field factor experiment results.

\begin{tabular}{|c|c|c|c|c|c|c|}
\hline Factors & Sum of deviation squares $\left(\mathrm{SS}_{\mathrm{i}}\right)$ & Freedom $(\mathrm{df})$ & Mean square deviation (MS) & $F_{\mathrm{A}}$ & $F_{0.05}(1,14)$ & Significance \\
\hline Drilling field (A) & 0.0003 & 1 & 0.0003 & 0.0003 & 4.60 & Not remarkable \\
\hline Error $(\mathrm{E})$ & 14.0679 & 14 & 1.0049 & - & - & - \\
\hline Sum $(T)$ & 14.0682 & 15 & - & - & - & - \\
\hline
\end{tabular}

TABLE 5: Average extraction radius at different extraction times.

\begin{tabular}{lcccccccc}
\hline Extraction time $(\mathrm{d})$ & 30 & 40 & 50 & 60 & 70 & 80 & 90 & 100 \\
\hline Extraction radius $(\mathrm{m})$ & 1.78 & 2.15 & 2.43 & 2.66 & 2.85 & 3.02 & 3.17 & 3.30 \\
Extraction time $(\mathrm{d})$ & 110 & 120 & 130 & 140 & 150 & 160 & 170 & 180 \\
Extraction radius $(\mathrm{m})$ & 3.42 & 3.53 & 3.63 & 3.73 & 3.82 & 3.89 & 3.97 & 4.05 \\
\hline
\end{tabular}

$4.05 \mathrm{~m}$, and the reasonable hole spacing is $8.10 \mathrm{~m}$. Considering that the thickness of $4^{-2}$ coal seam in the Jianxin coal mine changes greatly, when the thickness of the coal seam is large, gas drainage can be carried out in the form of double-layer drilling or double-layer staggered drilling.

\section{Conclusion}

(1) Through the field test, the original gas pressure of No. 24 and No. 25 drilling fields of $4^{-2}$ coal seam in the Jianxin coal mine was measured; then, the gas drainage borehole was precracked and drained, and the gas pressure of the test hole around the drainage hole decreased in varying degrees with time; the closer the distance to the drainage hole, the faster the gas pressure decreased, and the farther the distance, the slower the gas pressure decreased. The gas pressure of each test hole decreases exponentially with the drainage time.

(2) The relationship between the gas drainage radius and extraction time is obtained after $\mathrm{CO}_{2}$ presplitting in the No. 24 and No. 25 drilling field of the no. $4^{-2}$ coal seam in the Jianxin coal mine. The extraction radius increases in logarithmic function with increasing extraction time. The reasonable period of extraction in the no. $4^{-2}$ coal seam of the no. 4203 working face is 180 days, the effective radius of extraction is $4.05 \mathrm{~m}$, and the reasonable spacing of holes is $8.10 \mathrm{~m}$.

\section{Data Availability}

The data used to support the findings of this study are included within this article. Request for more details should be made to the corresponding author.

\section{Conflicts of Interest}

The authors declare that they have no conflicts of interest.

\section{Acknowledgments}

The authors acknowledge the financial support provided by the National Natural Science Foundation of China (Grant nos. 51704228 and 51704227).

\section{References}

[1] X. Bai, H. Ding, J. Lian et al., "Coal production in China: past, present, and future projections," International Geology Review, vol. 60, no. 5-6, pp. 535-547, 2018.

[2] G. Si and B. Belle, "Performance analysis of vertical goaf gas drainage holes using gas indicators in Australian coal mines," International Journal of Coal Geology, vol. 216, 2019.

[3] L. Yuan, "Strategic thinking of simultaneous exploitation of coal and gas in deep mining," Meitan Xuebao/Journal of the China Coal Society, vol. 41, no. 1, pp. 1-6, 2016.

[4] C. Ö. Karacan, F. A. Ruiz, M. Cotè, and S. Phipps, "Coal mine methane: a review of capture and utilization practices with benefits to mining safety and to greenhouse gas reduction," 
International Journal of Coal Geology, vol. 86, no. 2-3, pp. 121-156, 2011.

[5] Y. Liu, Z. Zhang, B. Deng, and M. Li, "Liquid carbon dioxide fracturing application and its effect on gas drainage in low permeability coal seams of underground coal mine," Energy Sources, Part A: Recovery, Utilization, and Environmental Effects, 2019.

[6] P. Wei, C. Huang, X. Li, S. Peng, and Y. Lu, "Numerical simulation of boreholes for gas extraction and effective range of gas extraction in soft coal seams," Energy Science \& Engineering, vol. 7, no. 5, pp. 1632-1648, 2019.

[7] L. Qin, C. Zhai, S. Liu, and J. Xu, "Mechanical behavior and fracture spatial propagation of coal injected with liquid nitrogen under triaxial stress applied for coalbed methane recovery," Engineering Geology, vol. 233, pp. 1-10, 2018.

[8] X. Yang, G. Wen, H. Sun et al., "Environmentally friendly techniques for high gas content thick coal seam stimulation-multi-discharge $\mathrm{CO}_{2}$ fracturing system," Journal of Natural Gas Science and Engineering, vol. 61, pp. 71-82, 2019.

[9] H. Liu and W. Hao, "Application research of liquid $\mathrm{CO}_{2}$ fracturing in coal seam penetration," IOP Conference Series: Earth and Environmental Science (EES), vol. 526, no. 1, 2020.

[10] C. Fan, S. Li, H. Zhang, and Z. Yang, "Rational boreholes arrangement of gas extraction from unloaded coal seam," Advances in Civil Engineering, vol. 2018, Article ID 1501860, 9 pages, 2018.

[11] G. Si, S. Durucan, J. Q. Shi, A. Korre, and W. Cao, "Parametric analysis of slotting operation induced failure zones to stimulate low permeability coal seams," Rock Mechanics and Rock Engineering, vol. 52, pp. 163-182, 2019.

[12] S. Liu, X. Li, D. Wang, M. Wu, G. Yin, and M. Li, "Mechanical and acoustic emission characteristics of coal at temperature impact," Natural Resources Research, vol. 29, pp. 1755-1772, 2020.

[13] Z. Yuan and Y. Shao, "Numerical modeling on hydraulic fracturing in coal-rock mass for enhancing gas drainage," Advances in Civil Engineering, vol. 2018, no. 8, 16 pages, Article ID 1485672, 2018.

[14] Y. Lu, H. Shen, B. Qin, L. Zhang, H. Ma, and T. Mao, "Gas drainage radius and borehole distance along seam," Journal of Mining and Safety Engineering, vol. 32, no. 1, pp. 156-162, 2015.

[15] Z. Junxiang, L. Bo, and S. Yuning, "Dynamic leakage mechanism of gas drainage borehole and engineering application," International Journal of Mining Science and Technology, vol. 28, no. 3, pp. 505-512, 2018.

[16] Z. Du and X. Yufei, "Study on carbon dioxide blasting mining and driving equipment and technology," Coal Science and Technology, vol. 44, pp. 36-42, 2016.

[17] H. Chen, Z. Wang, X. Chen, X. Chen, and L. Wang, "Increasing permeability of coal seams using the phase energy of liquid carbon dioxide," Journal of $\mathrm{CO}_{2}$ Utilization, vol. 19, pp. 112-119, 2017.

[18] C. Zheng, H. Li, M. Kizil et al., "Performance enhancement of horizontal underground-to-inseam gas drainage boreholes with double-phase-grouting sealing method for coal mining safety and clean gas resource," Journal of Natural Gas Science \& Engineering, vol. 76, 2020.

[19] S. J. Peng, C. L. Zhang, Y. Q. Liang, J. Xu, and D. Liu, "Physical simulation experiment on the evolution of gas pressure during CBM drainage," Meitan Xuebao/Journal of the China Coal Society, vol. 40, no. 3, pp. 571-578, 2015.

[20] H. J. Ji, Z. H. Li, Y. L. Yang, Z. Liu, and J. C. Yang, "Drainage radius measurement based on gas flow field," Caikuang $Y u$
Anquan Gongcheng Xuebao/Journal of Mining and Safety Engineering, vol. 30, no. 6, pp. 917-921, 2013.

[21] F. Wang, T. Ren, S. Tu, F. Hungerford, and N. Aziz, "Implementation of underground longhole directional drilling technology for greenhouse gas mitigation in Chinese coal mines," International Journal of Greenhouse Gas Control, vol. 11, pp. 290-303, 2012.

[22] H. Wen, X. Cheng, J. Chen et al., "Micro-pilot test for optimized pre-extraction boreholes and enhanced coalbed methane recovery by injection of liquid carbon dioxide in the Sangshuping coal mine," Process Safety and Environmental Protection, vol. 136, pp. 1-370, 2020.

[23] L. Hui, G. Chengwei, S. Yuanfang, and G. Shaoshuai, "Study on permeability improvement technology by injecting air into the gas drainage borehole in low-permeability coal seam," Advances in Civil Engineering, vol. 2018, Article ID 1912383, 7 pages, 2018.

[24] W. He, F. He, K. Zhang, Y. Zhao, and H. Zhu, "Increasing permeability of coal seam and improving gas drainage using a liquid carbon dioxide phase transition explosive technology," Advances in Civil Engineering, vol. 2018, no. 1, 15 pages, 2018.

[25] H. Wang, Z. Cheng, Q. Zou et al., "Elimination of coal and gas outburst risk of an outburst-prone coal seam using controllable liquid $\mathrm{CO}_{2}$ phase transition fracturing," Fuel, vol. 284, 2021.

[26] X. Zheng, X. Wang, J. Guo, D. Zhang, and B. Wang, "Experimental study on $\mathrm{CH}_{4}$ displacement from coal seam fractured by liquid CO2," International Journal of Heat and Technology, vol. 37, no. 1, pp. 212-218, 2019.

[27] D. I. W. Phillips, C. Osmond, H. Southall, P. Aucott, A. Jones, and S. T. Holgate, "Evaluating the long-term consequences of air pollution in early life: geographical correlations between coal consumption in 1951/1952 and current mortality in England and Wales," BMJ Open, vol. 8, no. 4, 2018. 